Type of the Paper (Article, Review, Communication, etc.)

\title{
Blueberry Mechanized Harvesting: Preliminary Results in the Italian Context
}

\author{
Luca Brondino ${ }^{1}$, Stefano Massaglia, Nicole Roberta Giuggioli* and Cristiana Peano
}

\author{
${ }^{1}$ Department of Agricultural, Forest and Food Sciences (DISAFA), University of Torino, Largo Paolo Braccini 2, \\ Grugliasco, 10095 Torino, Italy \\ * Correspondence: nicole.giuggioli@unito.it
}

\begin{abstract}
The object of this work is to report some preliminary results on the mechanical harvesting of blueberry fruits of $\mathrm{cv}$. Cargo $®$ in the Piedmont region, one of the most productive areas of Italy that is specialized for fresh blueberry production. The automatization of harvesting operations could represent a competitive advantage for the investigated area's blueberries supply chain, but could act as a limitation to maintaining the quality of fresh berries. A prototype machine and a commercial harvester (Easy Harvester ${ }^{\circledR}$ ) were compared to manual picking, considering harvest efficiency (share of loss), labor productivity and harvesting cost. In the indicated context, the cost of labor exceeds 2.00 euros per $\mathrm{kg}$ of sellable product. The use of the prototype allowed a $37 \%$ reduction of this cost, and the use of the Easy Harvester ${ }^{\circledR}$ allowed a reduction of about two thirds. It should be emphasized that these positive performances do not consider two other aspects: the reduction in the marketable volume (attributable to losses in the harvest and post-harvest phase), and the reduction in the net sale price by 0.30 euros due to the sorting/selection costs in the warehouse. In this study, we highlight how the transition to mechanical harvesting requires the transformation of several farming and warehouse operations, such as new crop varieties, new field configurations, and new packaging processes. However, a possible technical improvement of the Easy Harvester ${ }^{\circledR}$ machine could represent an opportunity for Italian companies in the planning of the production and marketing of berries, involving all actors of the supply chain. Further research on the use of mechanization in the sector must still be continued and supported.
\end{abstract}

Keywords : Vaccinum corymbosum; innovation; harvest; production; cost; prototype

\section{Introduction}

In the last 20 years, the free movement of goods, at a global level, has led to significant changes in the structure of the agri-food system. As a consequence, the scenario under which Italian fruit companies operate has undergone important changes, which have resulted in a considerable increase in competitive pressure at the international level. In this context, the contractual strength of demand of retailers, such as the modern distribution channel (MD), determines a considerable compression of the margins for both fruit farmers and warehouses, despite the growing attention paid by operators to planning and aggregation of offers [1]. This context forces producers to experiment with new solutions for all the steps of the supply chain, in order to reduce and limit the costs of production and to maintain competiveness at the international level $[2,3]$.

The most important factor that influences the cost of fresh fruit production (up to 50\%) is the labor cost, and hence the availability of workers is key [4]. A great challenge of recent years has been to harvest fruit and vegetables for the fresh market and the processing industry, while remaining competitive in the market. One opportunity related to this critical issue is the mechanization of harvesting procedures. Technology, at this step, 
could reduce the number of seasonal workers, improve productivity, reduce the cost of products, and improve producers' incomes [5,2]. Mechanization processes could also permit farms to solve the problem of shortages in seasonal worker availability for short periods of time (a few weeks), which represents a serious topic in the context of the COVID-19-related travel restrictions [3,6]. In their study, Seavert et al. [7] compared the mechanical harvest of cherries (Prunus Avium L.) with traditional methods, reporting that automatization can improve the incomes of the producers, whereas Baugher et al. [8] suggested innovation in harvest procedures can better organize workers. The automatization of the harvesting procedures of fruit trees is useful only for products for industry [3]; for the fresh market mechanical harvesting needs to be supported by new research in terms of field management and post-harvest techniques. Interesting results on mechanized harvesting have been achieved in different countries (Europe, Japan, and the U.S.A.), but some critical aspects, such as the higher cost of automatized harvesting and the quality of the products, still need to be solved [9]. In this last case, ripened fruits ready for picking (20-30\% of the products) are not detached and selected, because the machines do not recognize and identify them as ready to be harvested. Another critical issue is related to the relatively slow harvest rate, which means robot harvesting is not advantageous [3,9]. Regarding blueberries, world production has more than doubled in the last 10 years, reaching two million tonnes in 2020 (FAOSTAT, 2020) [10]. Several researchers have reported on the possibility of changing harvesting techniques and improving the automatization process [11]. The first studies on machines to automate the blueberry harvesting procedure were conducted in the U.S. at the end of the 1950s; in 1966, mechanical harvesters over the row (OTR) were introduced [12]. However, harvesters still need to be improved for the picking of berries for the fresh market [13]. The increase in investments in blueberry cultivation has led to the need for a large number of seasonal workers, especially at harvest time, which represents $90 \%$ of the total requirement for workers. Today, the great majority of blueberries for the fresh market are still harvested manually [14].

As reported by Brown et al. [15] and reiterated by www.eurofresh-distribution.com [16] this harvest typology needs up to 1200 hours of labor/ha/year, and this represents a critical factor of management due to the number of workers needed, the consequently high cost of labor, and the low labor efficiency. The mechanization of harvesting could affect the variable costs influencing the competiveness of agriculture in field production. A study conducted in 2012 showed that the use of a rotary blueberry mechanical harvester can reduce costs $(-85 \%)$ and improve the productivity of the work $(+6000 \%)$ [17]. The Italian area of blueberry crops was 370 ha in 2012, 460 ha in 2014, and 900 ha in 2019. Piedmont is the region in which berry production is most common, with 550 ha. [18]. The increase in production has led to a substantial change in the fresh blueberry supply chain, underlying a strong need for research and innovation in the whole sector due increasing consumer interest [19]. The per capita consumption of blueberries worldwide has practically doubled due to the growing awareness of consumers of the health benefits of this berry. The British are the European leaders in blueberry consumption $(0.86 \mathrm{~kg} /$ per capita) [20]. This differs significantly from the European average of $0.18 \mathrm{~kg} /$ person. However, the trend is positive: blueberry consumption is increasing in all European countries, especially in Germany, Switzerland, Benelux, and Scandinavia [21]. This evolution has entailed and will lead, in the coming years, to a radical change in the conception of blueberry production, which thank to the integration of income in the foothills, has become the main produce of numerous fruit farms located on the plains.

The objective of this study was to improve the knowledge on the applicability of mechanical picking harvesters for the highbush blueberry cv. Cargo ${ }$ in the Piedmont area, evaluating it in terms of economic performance. Manual picking was compared with two harvesting machines: one commercial machine already used in the north of Europe (Easy Harvester $\left.{ }^{\circledR}\right)$, and a prototype machine based on shaking. The comparison focused in 
particular on the economic and organizational aspects of labor, however some considerations were also developed on the qualitative aspects of the harvested product.

\subsection{Case Study}

The cooperative involved in this study (soc. coop. Agrifrutta member of OP Ortofruit Italia producers association) was selected to represent an important reality for the production of berries in Italy, which is actually increasing due to the national and international needs of the market. The cooperative has registered the greatest increase in surface area planted with blueberries and has developed, together with research organizations, innovation throughout the chain. It is a good example for improvement of the sector. Agrifrutta srl has passed, over a period of 10 years, from an organizational system type I, where the blueberries were packaged during the harvest directly by the producers and the product was immediately placed on the market with very reduced storage and conservation periods, to a type II system [22]. In type II, the supply chain involves refrigeration and modified atmosphere systems that allow the product to be on the market for a longer period of time, and for it to be packaged in storage. [19].

The improvement of agricultural techniques and the introduction of new commercial cultivars suitable for different growing areas and planting systems have also occurred, with the productivity improving from 9 to $15-20 \mathrm{t} / \mathrm{ha}-1$, and the marketable production from $22 \mathrm{t}$ to $146 \mathrm{t}$ (years 2015-2020).

Last Call ${ }^{\circledR}$, Blue Ribbon ${ }^{\circledR}$, and Cargo ${ }^{\circledR}$ are the varieties of highbush blueberry of recent introduction in the investigated area/case study, originating from the breeding programs of Fall Creek Company (Washington, US), a leader in advancements in this sector. Among the different varieties, this study considered the harvest of $\mathrm{cv}$. Cargo®: "A commercial variety intended to be machine harvested for both the fresh and processed markets. The variety has a very uniform crop of medium sized fruit with good flavor and excellent firmness, and has consistently high yields. 'Cargo' is a vigorous plant, with a narrow crown and upright growing habit" [23].

Cargo can be considered an ideal highbush blueberry plant for machine harvest, as first described by Galletta [24]. A machine-harvestable blueberry must have an upright bush architecture, few low-growing canes, a narrow crown, easy detachment of mature berries compared with immature berries, loose fruit clusters, a small stem scar, firm fruit, and a concentrated ripening period.

In this context, the need to reduce production costs of the fresh product through a reorganization of the workforce and proper management of innovation is one of the future objectives of the supply chain.

\section{Materials and Methods}

The study ran for two years (2018/19) in a commercial orchard of 1 ha in Lagnasco (Cuneo province). The three experimental plots (harvested via a prototype of the Easy Harvester ${ }^{\circledR}$ and manual harvesting) were formed by 600 plants at the IV-V year of age, of the cv Cargo ${ }^{\circledR}$, with a planting pattern of $1 \mathrm{~m}$ by $3.2 \mathrm{~m}$ ( 2875 plants/ha), with a trunk on the row $(0.15 \mathrm{~m}$ high), covered with mulching cloth (black plastic), and with grassed in- 
ter-rows. The orchard was equipped with a fertigation system and anti-hail nets. The production per hectare was 14.5 tons for the considered time period.

\subsection{Prototype Machine}

The prototype machine (Figure 1) was manufactured by Wgreen Tecnology sas (CN). It consisted of a self-propelled structure, equipped with four steering wheels, on which the seat intended for positioning the extendable arm used for shaking the plant was mounted on the rear. The end of the latter was composed of a comb which, inserted inside the plant, allowed a better and more widespread transmission of the shaking motion to the branches of the bush in order to facilitate the detachment of ripe fruit. The "shaking" movement of the comb is impressed on the insertion seat of the arm through a system of levers activated by the rotation of two drums, set in motion by a chain. This system is powered by a specific electric motor and, through a control panel, it is possible to vary both the speed and the frequency of shaking of the bush. The arm and the comb are made of steel, and the insertion of the latter into the plant is done manually. The entire machine is powered by electricity via two lithium batteries, which allow it to carry out an entire working day without the need for recharging. In addition, the remote-controlled steering system makes it easy to move the machine around the field. Its use involves the insertion of the fins inside the blueberry bush, the shaking of the latter for about $20 \mathrm{sec}$, the subsequent withdrawal of the arm, performed manually, and the movement. The machine, for a single set-up, is able to harvest one plant. The prototype does not include a system for harvesting the berries at the base of the row.

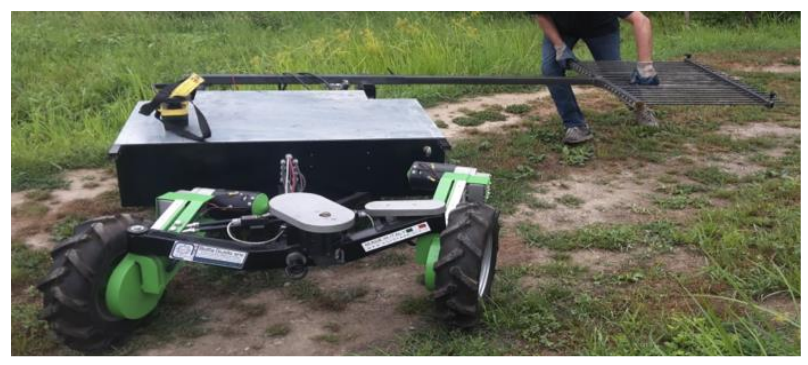

Figure 1. Prototype Machine for the blueberry harvest.

\subsection{Commercial Machine}

The Easy Harvester ${ }^{\circledR}$ commercial machine (Figure 2) was developed by the Driesvenplant BV Company with support from the International Blueberry Organization (IBO), Holland. The facilitator consists of two units that work simultaneously on both sides of the row. They can be separated from each other or joined by a straddling frame at the top that allows the entire structure to move hand in hand along the row. The single unit 
consists of a steel frame on which the aluminum box for collecting the fallen fruits is fixed. This frame rests on three rubber wheels, two fixed at the front and one steering at the rear, whereas in the version with the frame on the upper part, the number of wheels per single unit is reduced to two, since, being a single structure, the machine is more stable. The internal surfaces of the picker are inclined in such a way as to make the blueberry fall from the plant and roll towards the two boxes positioned at the base, which must be inserted inside the seats provided at the rear of the box. The picker, moreover, through a system of levers that can be operated manually, can be extended forward in both units so as to better adhere to the basal part of the plant, avoiding product losses on the ground. The end of the box that comes into contact with the row is equipped with a brush, made up of very elastic plastic bristles, which allows the two units of the machine to join more efficiently to the base of the plants during the harvest. Furthermore, this system allows Easy Harvester ${ }^{\circledR}$ to always be in close contact with the row and not damage the bush, especially in the basal lignified part when moving the machine. The Easy Harvester ${ }^{\circledast}$ is equipped with a seat for the transport of empty crates on the front wheel frame, while full ones must be left on the ground along the row and taken away from the field at a later time. The machine, for a single set-up, collects from two plants at the same time, and both the shaking for the fruit to fall and the handling of the facilitator in the field must be performed manually (Figure 3).

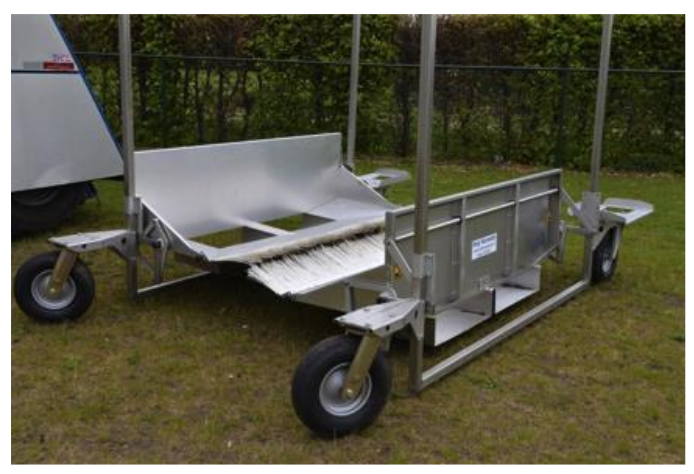

Figure 2. Easy Harvester ${ }^{\circledR}$ commercial machine.

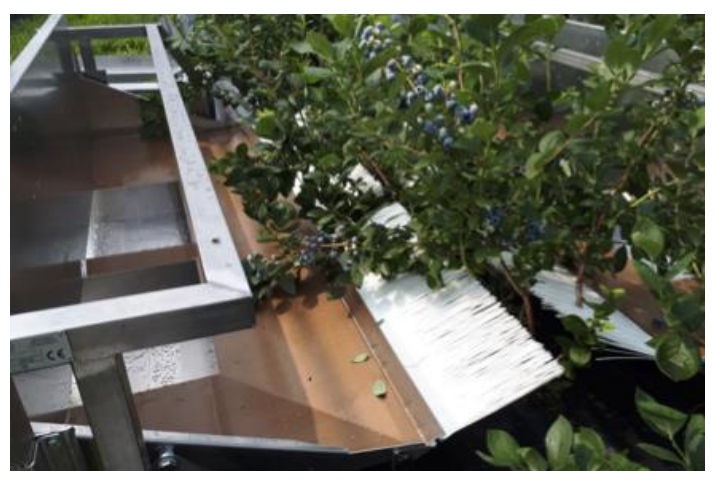

Figure 3. Blueberries collecting Easy Harvester®.

\subsection{Data Collection}

This study was carried out on each plot for each type of harvesting tested, at three different picking times (in July, spaced 10 days apart). For each picking, the technical/productive and economic parameters were calculated.

For the first evaluation we considered: the average harvested production per plant, the number of workers involved in the harvesting, the number of plants harvested at the 
same time, the productivity of the single working unit, and, for the two mechanized harvestings, the time of the single set-up. Furthermore, in the post-harvest step, the percentage of loss in the warehouse was quantified. Data were directly collected in the orchard during the harvesting time (Tables 1 and 2).

The economic evaluations considered all costs associated with the harvest operations for each of the trials. As an indicator of rentability (calculated for each harvest typology), the difference between the values of the total sellable output and the harvesting costs was used. The values of the total sellable output was the revenue from sales of blueberries, where the yields considered were those obtained in the field experiments and prices were based on the average prices obtained by the farmer in the last two years for hand-harvested blueberries $(4.00 € / \mathrm{kg})$. A sensitivity analysis of the revenues was undertaken by testing the effect of consistent variations in prices (up to $+/-25 \%$ ), in consideration of the fact that the prices of berry fruits in the last few years have started to face consistent fluctuations $[25,26]$. In addition, for mechanically harvested fruits, from the purchase price, the value of processing operations made at the warehouse $(0.30 € / \mathrm{kg})$ was subtracted. This amount corresponds to the processing costs charged by the warehouse to the farmer in the period 2018/2019 (data provided by Agrifrutta soc. coop.).

Table 1. Technical data of production of blueberries cv. Cargo during total harvest

\begin{tabular}{llrrr}
\hline Technical data of production & Unit & Manual & Prototype & Easy Harvester \\
\hline Production/plant & Kg & 5 & 5 & 5 \\
Plants*ha $^{-1}$ & plants*ha $^{-1}$ & 2875 & 2875 & 2875 \\
Harvest & number of picking & 3 & 3 & 3 \\
Workers for the harvest & Unit & 12 & 3 & 4 \\
Harvested plants in the same time & Unit & & 2 & 2 \\
Time to set up & Min & & 3.5 & 2.6 \\
Performance of harvester: & kg*h-1 $^{*}$ & $5-38$ & 19.05 & 19.35 \\
Picking hours & total hours/worker*ha-1 & 2674 & 755 & 743 \\
Days of harvesting & Total days/worler*ha-1 & 27.9 & 31.4 & 23.2 \\
Production*ha-1: & kg*ha-1 & 14375 & 14375 & 14375 \\
\% berries loss & $\%$ & 0 & 28.3 & 15.1 \\
Sale production*ha & & 14375 & 10307 & 12204 \\
\hline
\end{tabular}


Table 2. Technical data of production of blueberries cv. Cargo during at the different picking times

\begin{tabular}{|c|c|c|c|c|c|c|c|c|c|c|}
\hline & & \multicolumn{3}{|c|}{ I harvest time } & \multicolumn{3}{|c|}{ II harvest time } & \multicolumn{3}{|c|}{ III harvest time } \\
\hline & Unit & Manual & Prototype & Easy Harvester ${ }^{\circledR}$ & Manual & Prototype & Easy Harvester ${ }^{\circledR}$ & Manual & Prototype & Easy Harvester $\AA$ \\
\hline Harvest & $\%$ & $30 \%$ & $30 \%$ & $30 \%$ & $42 \%$ & $50 \%$ & $50 \%$ & $28 \%$ & $20 \%$ & $20 \%$ \\
\hline Performance of harvest & $\mathrm{kg}^{*} \mathrm{~h}^{-1}$ & 5.0 & 17.1 & 15.0 & 6.0 & 28.6 & 33.3 & 5.0 & 11.4 & 12.0 \\
\hline $\begin{array}{c}\text { Plants harvested in the } \\
\text { same time }\end{array}$ & Unit & - & 2 & 2 & - & 2 & 2 & - & 2 & 2 \\
\hline Time to set up & Min & - & 3.5 & 3.0 & - & 3.5 & 2.3 & - & 3.5 & 2.5 \\
\hline Production*ha ${ }^{-1}$ & $\mathrm{~kg}^{*} \mathrm{ha}^{-1}$ & 4312.5 & 4312.5 & 4312.5 & 6037.5 & 7187.5 & 7187.5 & 4025.0 & 2875.0 & 2875.0 \\
\hline$\%$ of berries loss & $\%$ & 0.0 & 40.0 & 30.0 & 0.0 & 27.0 & 9.0 & 0.0 & 14.0 & 8.0 \\
\hline Sellable production & $\mathrm{kg}^{*} \mathrm{ha}^{-1}$ & 4312.5 & 2587.5 & 3018.8 & 6037.5 & 5246.9 & 6540.6 & 4025.0 & 2472.5 & 2645.0 \\
\hline Picking hours & $\begin{array}{l}\text { total hours/ } \\
\text { worker } \mathrm{s}^{*} \mathrm{ha}^{-1}\end{array}$ & $862 . .5$ & 251.6 & 287.5 & 1006.3 & 251.6 & 215.6 & 805.0 & 251.6 & 239.6 \\
\hline Picking days & $\begin{array}{l}\text { Total days/ } \\
\text { worker *ha-1 }\end{array}$ & 9.0 & 10.5 & 9.0 & 10.5 & 10.5 & 6.7 & 8.4 & 10.5 & 7.5 \\
\hline
\end{tabular}

\section{Results}

The overall costs for each of the three tests carried out are shown in Tables 3 and 4 . The overall estimated costs for manual harvesting are significantly higher than for the two mechanical harvesting tests carried out. The cost of labor exceeds 2.00 euros per $\mathrm{kg}$ of sellable product (Table 4). The use of the prototype allows a $37 \%$ reduction in this cost, and the use of the Easy Harvester ${ }^{\circledR}$ allows a reduction of about two thirds of these costs. It should be emphasized that these positive performances in terms of unit production costs do not consider two critical issues: the reduction in the marketable volume (attributable to the losses highlighted by the experiments in the harvest and post-harvest phase), and the reduction in the net sale price of 0.30 euros per $\mathrm{kg}$ due to the sorting/selection costs charged by the warehouse to the farmer. In order to achieve an overall comparison of the effect on the margins of the three harvesting techniques, the margins/rentability (as defined in M\&M) that can be obtained for each of the experiments were determined by analyzing a range of net sales prices, ranging from 3 to 5 euros per kilogram. The collection technique that guarantees, for any price level analyzed, the highest margin is the Easy Harvester ${ }^{\circledR}$ (Table 5). The prototype, due to high percentages of product loss, for most of the price scenarios analyzed, is the least convenient; only for prices equal to or lower than 3.40 euros does it become competitive compared to manual harvesting. However, the analysis of the obtainable margins conducted for each picking highlights how the best overall results of the Easy Harvester ${ }^{\circledR}$ are mainly due to the performance in the second picking. In fact, as shown in Table 5, manual harvesting guaranteed higher margins with medium-high prices (4.00-5.00 euros) in the first period, and performed increasingly well in the third period.

The economic advantages reported are reflected in the technical performances highlighted by the Easy Harvester ${ }^{\circledR}$. Mechanized harvesting, in addition to allowing a 
consistent reduction of hours of human labor, minimizes the risk of labor shortages, allowing for greater specialization of the company's workforce. Finally, the substantial reduction in the necessary manpower $(-67 \%)$ allows for better management of workers at the company level [27]. Furthermore, the possibility of completing each harvest (II time)

\begin{tabular}{|l|l|l|l|l|c|}
\hline & Unit & Total costs & Cost of I harvest time & Cost of II harvest time & Cost of III harvest time \\
\hline
\end{tabular}

in fewer days allows the farm to harvest the product with greater homogeneity of the product in terms of maturity, and with greater ease of management of the product even in the post-harvest phase. Additionally, a further technical aspect emerges: the reduced picking time allows more efficient and effective management of emerging entomological problems (Drosophyla suzukii) [28].

The strong variability in prices found in the last three commercial years (2018-2020) seems to further support the results highlighted by the test, as in the face of the impossibility of the company to reduce production costs, the margins obtainable in both scenarios with high prices and those with declining prices show a greater overall associated rentability for the Easy Harvester ${ }^{\circledR}$. An analysis of the data relating to the necessary investment costs further highlights the suitability of the Easy Harvester ${ }^{\circ}$. In this respect, this form of mechanized harvesting also presents undoubted advantages in terms of investments required compared to another common mechanized solution: OTR. This mechanization solution seems to be the one that best suits the analyzed production context compared to other solutions on the market, and was designed for the specific needs of North American producers [27].

The differences in technique used for the harvesting of fruits affects the state of dehydration of the berries in post-harvest management. The automatization process increases the percentage of damaged fruits; damage occurred less with manual harvesting at all three picking times. However, at the end of the storage period, the percentage of shriveled fruit was also found to be tolerable for the product harvested with the Easy Harvester ${ }^{\circledR}$. Considering the overall state of the berries, the evaluation of the maintenance of the waxy bloom is one of the most important parameters for blueberries [29,30]. The cv. Cargo is characterized by a large quantity of wax that covers the skin, so the loss of external quality is more pronounced. The skins of berries from mechanical harvesting lost $30-40 \%$ more wax than the controls (manual picking). This was due to the high amount of contact that the berries had with the surfaces of the box, and the subsequent manual selection to which they were subjected. However, at the end of storage time, berries harvested manually and mechanically both showed good visual commercially quality.

Table 3. Overall costs of harvesting operations from Agrifrutta soc coop database (average 2018-2019).

\begin{tabular}{llrrr}
\hline Production factors & Unit & Manual harvest & Prototype & Easy Harvester ${ }^{\circledR}$ \\
\hline Non-specialized employee & $€^{*} h^{-1}$ & $€ 10.98$ & $€ 10.98$ & $€ 10.98$ \\
Machine market price & $€$ & & $€ 60,000.00$ & $€ 5,000.00$ \\
Expected years of life of the machine & years & 15 & 15 \\
Market price lithium batteries & $€$ & $€ 2,400.00$ & \\
Expected years of battery life & years & 5 & \\
Electricity cost for single recharge & $€^{*}$ days $^{-1}$ & $€ 2.00$ & \\
Machine maintenance & $€^{*}$ years-1 $^{-1}$ & & $€ 100.00$ & $€ 200.00$ \\
\hline
\end{tabular}




\begin{tabular}{|c|c|c|c|c|c|c|c|c|c|c|c|c|c|}
\hline & & $\begin{array}{l}\overline{\widetilde{J}} \\
\text { స్ } \\
\text { ¿ }\end{array}$ & 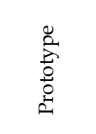 & 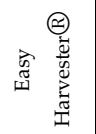 & 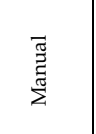 & 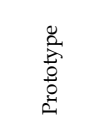 & 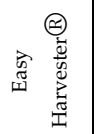 & 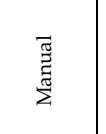 & 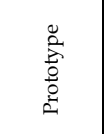 & 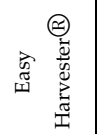 & 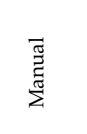 & 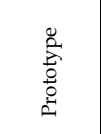 & 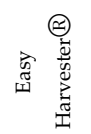 \\
\hline Total Fixed cost & & - & $4,580.00$ & 533.33 & - & $1,526.67$ & 177.78 & - & $1,526.67$ & 177.78 & 0.00 & $1,526.67$ & 177.78 \\
\hline Machine depreciation & $€^{*}$ year-1 & - & $4,000.00$ & 333.33 & - & $1,333.33$ & 111.11 & - & $1,333.33$ & 111.11 & 0.00 & $1,333.33$ & 111.11 \\
\hline Batteries depreciation & $\epsilon^{*}$ year- ${ }^{1}$ & - & 480.00 & - & - & 160.00 & - & - & 160.00 & - & - & 160.00 & - \\
\hline Machine maintenance & $\epsilon^{*}$ year-1 & - & 100.00 & 200.00 & - & 33.33 & 66.67 & - & 33.33 & 66.67 & 0.00 & 33.33 & 66.67 \\
\hline Total Variable costs & $€^{*}$ year- & $29,357.78$ & $8,349.36$ & $8,154.94$ & $9,470.25$ & $2,783.12$ & $3,156.75$ & $11,048.63$ & $2,783.12$ & $2,367.56$ & $8,838.90$ & $2,783.12$ & $2,630.63$ \\
\hline Electricity cost & $€^{*}$ year- ${ }^{1}$ & - & 62.89 & - & - & 20.96 & - & - & 20.96 & - & - & 20.96 & - \\
\hline Labor cost & $\epsilon^{*}$ year-1 & $29,357.78$ & $8,286.47$ & $8,154.94$ & $9,470.25$ & $2,762.16$ & $3,156.75$ & $11,048.63$ & $2,762.16$ & $2,367.56$ & $8,838.90$ & $2,762.16$ & $2,630.63$ \\
\hline Fixed+variable costs: & $€^{*}$ year- ${ }^{1}$ & $29,357.78$ & $12,929.36$ & $8,688.27$ & $9,470.25$ & $4,309.79$ & $3,334.53$ & $11,048.63$ & $4,309.79$ & $2,545.34$ & $8,838.90$ & $4,309.79$ & $2,808.40$ \\
\hline
\end{tabular}

Table 4. Overall costs for the different harvesting time from Agrifrutta soc coop database (average 2018-2019). 
Table 5. Rentability for the different harvesting time

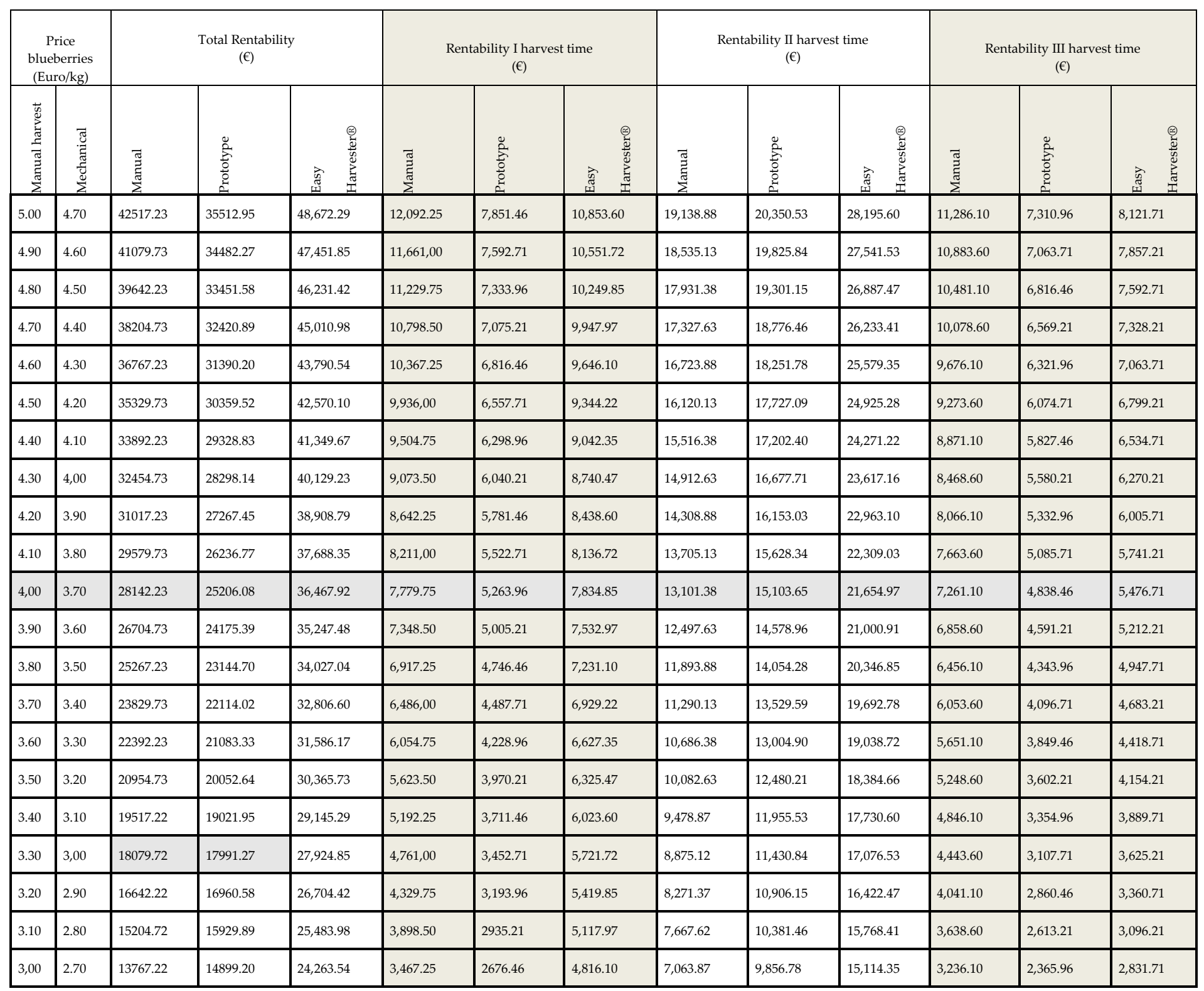

\section{Conclusions}

Labor constraints are continually increasing, and with that comes the need to develop alternative mechanical harvesting technologies that are cost effective for producers and can guarantee a wholesome product with comparable quality to hand-harvested blueberries. Preliminary results from this study have underlined some interesting aspects in the mechanical harvesting of the blueberry cv. Cargo ${ }^{\circledR}$. The use of the commercial machine Easy Harvester ${ }^{\circledR}$ represents an opportunity to evaluate the process of automatization in terms of the harvest technique for blueberries in the investigated context. Some suggestions could be proposed to the farmer at different times of harvesting. In terms of the picking time for $\mathrm{cv}$. Cargo ${ }^{\circledR}$, different harvesting methods can be successful. The Easy Harvester ${ }^{\circledR}$ machine could be useful for the second picking, which corresponds to the highest productivity and the lowest loss of berries in a harvesting period, espe- 
cially as there is a high demand for workers to pick other crops in the same area. Due the low homogeneity in the quality (in terms of ripening time) and quantity of fruit production in the other harvesting times (early and late productions), manual operations could be used to limit the losses during those pickings. Some technical aspects of the commercial machine could be improved to increase the performance in the field:

The insertion of a motorized system (electric motor) to move the machine, to reduce the actual physical work of the operators;

The use of lighter materials than steel;

- The use of tires with a larger diameter to adapt the machine to farms with slopes, and the insertion of a system to block them;

- $\quad$ The insertion of a system to modulate the inclination of the collector box according to the field, in such a way as to allow the latter to fit better at the base of the row.

The technical performance of the machine could be successful if the management of berry production were improved, considering the entire supply chain. The types of plants and the techniques of production in the field could be improved by following the suggestions of Peterson et al. and Panfilova et al. [31,32]:

- $\quad$ Reduce the expansion of the branches using steel wires in the field;

- $\quad$ Prune to promote a vertical architecture of the plant, reducing the number of branches in the basal part and pushing the production to the upper part of the bush. This will make it possible to increase the adherence of the collector box to the row, facilitate the insertion of the latter at the base of the plant, facilitate the shaking work of the harvesters, increase the productivity of the machine, and reduce the loss of ground product.

The integration of berries harvested manually and mechanically suggests some strategies for storage and commercialization of blueberries:

- Store berries mechanically harvested for a short period of time (max 15 days);

- Blueberries that have been manually harvested should be stored in modified atmosphere (A.M.) to extend the product life (storage 30-40 days).

As reported by Huffman et al. [33], switching to mechanical harvesting frequently requires the transformation of a farming operation, including new crop varieties, new field configurations, and new packing processes.

In conclusion, it can be suggested that the technical improvement of the Easy Harvester $^{\circledR}$, with the evolution of management in the pre and post-harvest of the blueberry sector, could represent an opportunity for Italian companies in the future planning of berry production and commercialization, involving all the actors of the supply chain. The application of mechanization research to the sector requires continued research and support.

Author Contributions: L. B., C. P. and S. M. designed the research, interpreted results and wrote the paper. L. B. and N. G. collected data, collaborated in the literature review and checked results. All authors read and approved the final manuscript, analysed the data and participated jointly in the discussion. All authors have read and approved the final manuscript.

Acknowledgments: We would like to thank all of the producers, professionals, operators, colleagues and collaborators that actively participated in the research project.

Funding: This article summarises an innovation process funded over the years by Ortofruititalia perational Programme, UE.

Conflicts of Interest: The authors declare no conflict of interest. The funders had no role in the design of the study, in the collection, analyses, or interpretation of data, in the writing of the manuscript, or in the decision to publish the results 


\section{References}

1. Capitanio, F.; Coppola, A.; Pascucci, S. Product and process innovation in the Italian food industry. Agribusiness 2010, 26, 503-518.

2. Sarig, Y. Mechanical Harvesting of Fruit: Past Achievements, Current Status and Future Prospects. Acta Hort. 2012, 965, 163-170.

3. Sarig, Y. Mechanized Fruit Harvesting œ Site Specific Solutions. Information and Technology for Sustainable Fruit and Vegetable Production FRUTIC 05, 12-16 September (2005), Montpellier (France), 237-247.

4. Ferreira, M.D.; Sanchez, A.C.; Braunbeck, O.A.; Santos, E.A. Harvesting fruits using a mobile platform: a case study applied to citrus. Engenharia Agrícola 2018, 38, 293-299

5. Holt, J.S. Implications of reduced availability of seasonal agricultural workers on the labor intensive sector of U.S agriculture. A Paper presented at the ASAE/CSAE Annual International Meeting, Toronto, Ontario, Canada.1999

6. Cortignani, R.; Carulli, G.; Dono, G. COVID-19 and labour in agriculture: Economic and productive impacts in an agricultural area of the Mediterranean. Italian Journal of Agronomy 2020, 15(2), 172-181.

7. Seavert, C.F.; Whiting, M.D. Comparing the economics of mechanical and traditional sweet cherry harvest. Acta Hort 2011, 903, 725-730.

8. Baugher, T.; Schupp, J.; Lesser, K.; Harsh, R.M.; Lewis, K.; Seavert, C.; Auvil, T. Mobile platforms increase orchard management efficiency and profitability. Acta Hort 2009, 824, 361-364.

9. Zujevs, A.; Osadcuks, V.; Ahrendt, P. Trends in robotic sensor technologies for fruit harvesting: 2010-2015. Procedia Computer Science 2015, 77, 227-233.

10. FAO 2020 http://www.fao.org/faostat/en/\#home (accessed on 15 December 2020)

11. Williamson, J.G.; Cline, W.O. Mechanized harvest of southern highbush blueberries for the fresh market: an introduction and overview of the workshop proceedings. HortTechnology 2013, 23, 416-418.

12. Monroe, G.E. ; Levin, J.H. Mechanical harvesting of cultivated blueberries. Trans.Amer. Soc. Agr.Eng 1966, 9 , 4-5.

13. Moggia, C.; Graell, J.; Lara, I.; González, G.; Lobos, G.A. Firmness at harvest impacts postharvest fruit softening and internal browning development in mechanically damaged and non-damaged highbush blueberries (Vaccinium corymbosum L.). Frontiers in plant science 2017, 8, 535).

14. Eklund, B. Blueberry Statistics; National Agricultural Statistics Service. United States Department of Agriculture: Washington, DC, USA, 2016, 9. Available (accessed on 15 November 2020):

http://www.nass.usda.gov/Statistics

15. Brown, G.K.; Schulte, N.L.; Timm, E.J.; Beaudry, R.M.; Peterson, D.L.; Hancock, J.F.; Takeda, F. Estimates of mechanization effects on fresh blueberry quality. Appl. Eng. Agric. 1996, 12, 21-26.

16. https://www.eurofresh-distribution.com/news/bumper-harvest-chiles-blueberry (accessed on 15 November 2020)

17. Yu, P.; Li, C.; Takeda, F.; Krewer, G.; Rains, G.; Hamrita, T. Quantitative evaluation of a rotary blueberry mechanical harvester using a miniature instrumented sphere. Computers and Electronics in Agriculture 2012, 88, 2531. 
18. Centro Servizi Ortofrutticoli (CSO): Piccolo Frutti-Report. 2012. Available on-line: http://www.csoservizi.com/dettagli_documento.php?id=1350 (accessed on 10 November 2020).

19. Peano, C.; Girgenti, V.; Baudino, C; Giuggioli, N.R. Blueberry supply chain in Italy: management, innovation and sustainability. Sustainability 2017, 9, 261-278.

20. Brazelton, 2019. VII International Blueberry Conference, Poland 7-8. March 2019).

21. Podymniak, M. Blueberry Europe - the market is going to change. 2019. Available on-line: https://www.freshplaza.com/article/9074068/blueberry-europe-the-market-is-going-to-change/

22. Verdouw, C.N.; Beulens, A.J.M.; Trienekens, J.H.; Wolfert, J. Process modelling in demand-driven supply chains: A reference model for the fruit industry. Comput. Electron. Agric. 2010, 7, 3174-3187

23. Brazelton, D.M. ; Wagner, A.L. US20130239260P1. Patent in United States: Blueberry plant named 'CARGO.

24. Galletta, G.J. 1975. Blueberries and cran- berries, p. 154-195. In: J. Janick and J.N. Moore (eds.) Advances in fruit breeding. Purdue Univ. Press, West Lafayette

25. Italian berry: la mappa globale dei prezzi settimanali dei mirtilli. Available on-line:

https://italianberry.it/2021/02/02/la-mappa-globale-dei-prezzi-settimanali-dei-mirtilli/ (accessed on 15 November 2020).

26. Fresh fruit portal: EU imposes retaliatory tariffs on U.S. fresh, frozen blueberries. Available on-line: https://www.freshfruitportal.com/news/2020/11/16/eu-imposes-retaliatory-tariffs-on-u-s-fresh-frozen-blueberr ies/(accessed on 17 November 2020).

27. Sargent, S.A.; Takeda, F.; Williamson, J.G.; Berry, A.D. Harvest of southern highbush blueberry with a modified, Over-The-Row mechanical harvester: use of handheld shakers and soft catch surfaces, Agriculture, 2020, 10,4 .

28. Margaret, T. Lewis, Kelly A Hamby Optimizing caneberry spray coverage for Drosophila suzukii (Diptera: Drosophilidae) management on diversified fruit farms. Journal of Economic Entomology, 2020, 113, $2820-2831$.

29. Takeda, F.; Yang, W.Q.; Li, C.; Freivalds, A.; Sung, K.; Xu, R.; Hu, B.; Williamson, J.; Sargent, S. Applying new technologies to transform blueberry harvesting. Agronomy 2017, 7, 33.

30. Chu, W.; Gao; H., Chen, H.; Fang, X.; Zheng,Y. Effects of cuticular wax on the postharvest quality of blueberry fruit. Food chem. 2018, 15, 68-74.

31. Peterson, D. L.; Takeda, F. Feasibility of mechanical harvesting fresh market quality eastern thornless. Engineering in Agriculture, 2003, 19, 25-30.

32. Panfilova, O.; Kalinina, O.; Golyaeva, O.; Knyazev, S.; Tsoy, M. Physical and mechanical properties of berries and biological features of red currant growth for mechanized harvesting. Res. Agr. Eng., 2020, 66, 156-163.

33. Huffman, W.E. The status of labor-saving mechanization in U.S. fruit and vegetable harvesting. Iowa State University, Department of Economics Working Paper \#12009, May. 